DOI: https://doi.org/10.15688/lc.jvolsu.2018.3.9

UDC 336.2

LBC 67.402

\title{
THE SIGN OF AUTHORITATIVENESS IN TAX LEGAL RELATIONS
}

\author{
Sergey A. Yadrikhinskiy \\ North-Western Institute (Branch) of Kutafin Moscow State Law University, Vologda, Russian Federation
}

Introduction: the questions concerning the study of the concept of tax legal relationship have both theoretical and applied importance. It is the correct understanding of the essence of tax legal relationship and its essential features that determine not only the solution of a separate tax dispute, but also the formation of an effective tax policy. Currently, there is an idea of tax legal relationship as a relationship of power and subordination, whose main content is the taxpayer's obligation to pay tax to the budget. This understanding was particularly characteristic of the initial stage of development of the modern tax system. The purpose of this study is to determine the role and measures of "authoritativeness" in the extended perimeter of tax relations in all their diversity and, above all, in the partnership model of the relationship between the taxpayer and the state, but also in the tax interactions where the taxpayer acts in the creditor status, use the parlance of the civilist. The methodological framework for the research consists of various general and special methods to cognize the legal reality phenomena. Among the particularly significant ones are legal dogmatic and comparative law methods. Results: with the development of the level of the state confidence in the taxpayer and dispositive beginnings in tax relations, the sign of authoritativeness shifts from the leading positions and begins to play an auxiliary role. When the taxpayer fulfils his/her tax obligations in good faith, the power component remains completely unclaimed. Moreover, it is inappropriate to talk about authoritativeness in those tax relations where the tax authority acts as an obligator. Conclusions: as a result of the conducted research, the author comes to the conclusion that the manifestation of authority in the sense of subordination of the taxpayer's will only takes place in extraordinary circumstances: when deviating from the legitimate model of the taxpayer's behavior.

Key words: tax legal relationship, taxpayer, tax authority, authoritative subordination, obligator, power to require.

Citation. Yadrikhinskiy S.A. The Sign of Authoritativeness in Tax Legal Relations. Legal Concept, 2018, vol. 17, no. 3, pp. 63-69. DOI: https://doi.org/10.15688/lc.jvolsu.2018.3.9

УДК 336.2

ББК 67.402

\section{ПРИЗНАК ВЛАСТНОСТИ В НАЛОГОВЫХ ПРАВООТНОШЕНИЯХ}

\author{
Сергей Александрович Ядрихинский \\ Северо-Западный институг (филиал) Университета им. О.Е. Кутафина (МГЮА), \\ г. Вологда, Российская Федерация
}

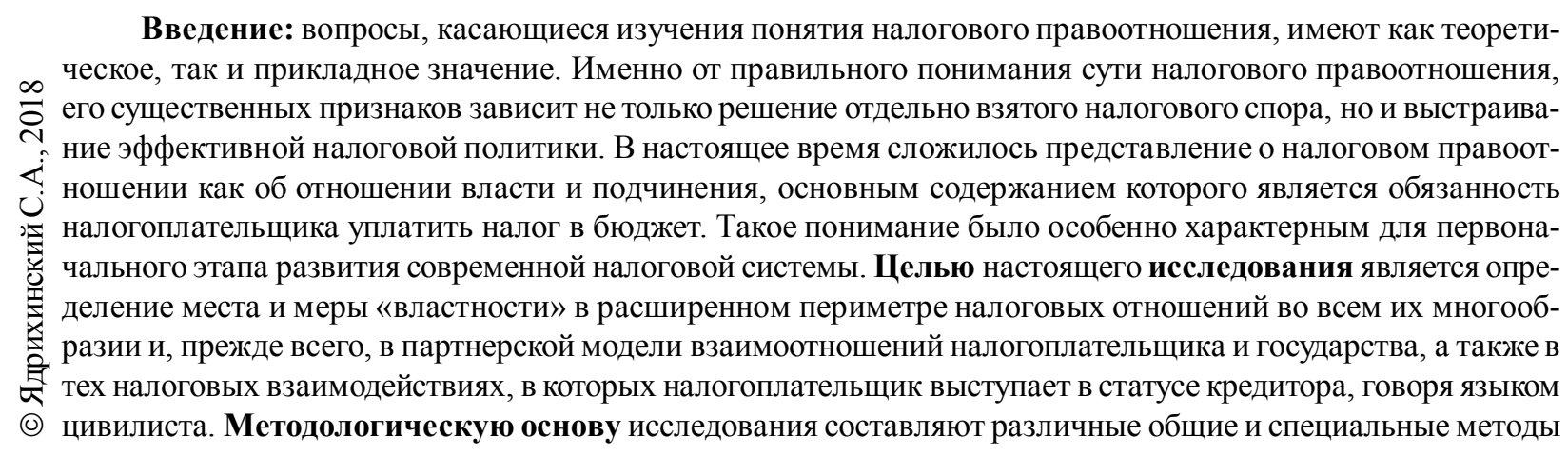




\section{ТЕОРИЯ И ПРАКТИКА ГОСУДАРСТВЕННО-ПРАВОВОГО РАЗВИТИЯ}

познания явлений правовой действительности. Среди них особо значимыми являются юридико-догматический и сравнительно-правовой методы. Результаты: с развитием как уровня доверия государства к налогоплательщику, так и диспозитивных начал в налоговых отношениях признак властности смещается с лидирующих позиций и начинает играть вспомогательную роль. При добросовестном исполнении налогоплательщиком налоговых обязательств властный компонент остается совсем невостребованным. Тем более неуместно говорить о властности в тех налоговых отношениях, в которых налоговый орган выступает в роли обязанного лица. Выводы: в результате проведенного исследования автор приходит к выводу, что проявление власти в смысле подчинения воли налогоплательщика имеет место лишь в исключительных случаях: при отклонении от правомерной модели поведения налогоплательщика.

Ключевые слова: налоговое правоотношение, налогоплательщик, налоговый орган, властное подчинение, обязанное лицо, правомочие требовать.

Цитирование. Ядрихинский С. А. Признак властности в налоговых правоотношениях // Legal Concept $=$ Правовая парадигма. -2018. - Т. 17, № 3. - C. 63-69. - DOI: https://doi.org/10.15688/lc.jvolsu.2018.3.9

\section{Введение}

Понятие «налоговое правоотношение» является одной из самых фундаментальных правовых категорий в финансовом (налоговом) праве, и в то же время, ввиду отсутствия единства в понимании правовой сущности этого феномена, остается нерешенной научной проблемой. Содержание любого понятия раскрывается через существенные признаки. Одним из таких признаков является властность или властно-имущественный характер налоговых правоотношений. Именно этот признак и является предметом настоящего исследования.

\section{Традиционные представления}

\section{о властности в налоговых отношениях}

В своих актах Конституционный суд РФ неоднократно указывал, что налоговые правоотношения основаны на властном подчинении налогоплательщика налоговому органу и предполагают субординацию сторон, одной из которых (налоговому органу, действующему от имени государства) принадлежит властное полномочие, а другой (налогоплательщику) - обязанность повиновения $[12 ; 4]$.

На властный, властно-имущественный характер налоговых правоотношений обращается внимание и в доктринальных источниках $[8$, c. $30 ; 14$, с. $42 ; 17$, с. $346 ; 20$, с. 7$]$.

Доминирование властного признака в налоговых отношениях пришло из советской школы финансового права. Профессор Е.А. Ровинский специфику финансово-правовых (в том числе налоговых) отношений видел в их властно-имущественном характере
$[1$, с. $24 ; 15$, с. 43$]$. Ученые того времени трактовали налоговое правоотношение достаточно узко и исключительно в рамках этатистской доктрины. С.Д. Цыпкин основным содержанием налогового правоотношения считал одностороннее обязательство налогоплательщика внести в государственный бюджет определенную денежную сумму [19, с. 28]. В дальнейшем эта мысль была повторена [16, с. 173].

Такой подход отвечал духу того времени и укладу экономики. Налогоплательщик не мог выступать в роли лица, требующего от государства какой-либо компенсации, например, за несвоевременно возвращенный излишне уплаченный налог.

\section{Власть налогового органа или власть закона?}

Сегодня налоговые отношения неоднородны, круг взаимодействий налогоплательщика с налоговым органом значительно расширился.

В связи с разнообразием и многогранностью налоговых отношений значение признака «властности» в них не следует преувеличивать. В ст. 2 НК РФ законодатель выделил четыре группы отношений, регулируемых законодательством о налогах и сборах, и только отношениям по установлению, введению и взиманию налогов, сборов и страховых взносов в буквальном смысле прямо придал властный характер.

Общим условием существования власти является способность оказывать воздействие на волю подвластного лица. Власть имеет ме- 
сто только в тех ситуациях, где результаты деятельности взаимодействующих субъектов изначально не предопределены [18, с. 126].

В.Г. Ледяев так описал формулу влас$m u$ : “"А” не имеет власти над “Б”, если “А” может заставить “Б” делать только то, что “Б” уже делает и без его вмешательства или будет делать независимо от “А”» [3, с. 160].

Несмотря на то что налоговые отношения детерминированы публично - правовым характером налога и фискальным суверенитетом государства, налогоплательщик, как участник налоговых правоотношений, не во всех случаях субординирован с налоговым органом. Последний далеко не всегда наделен возможностью директивно управлять поведением налогоплательщика. Налогоплательщик уплачивает налоги в силу требования закона, а не властного предписания налогового органа (хотя это и не исключается), и в случае добросовестного исполнения своей обязанности властный момент воздействия вообще может быть не затронут.

Пожалуй, правильнее здесь говорить о власти закона (а не налогового органа), в которой равным образом оказываются как налоговый орган, так и налогоплательщик: они оба равны перед законом и подчиняются только его (закона) предписаниям.

Следует учесть, что в некоторых случаях инициатором налоговых отношений выступает сам налогоплательщик. Таким примером может выступать п. 3.1 ст. 61 НК РФ, предусматривающий изменение срока уплаты налога и (или) сбора: заинтересованное лицо подает заявление о предоставлении отсрочки или рассрочки и (или) заявление о предоставлении инвестиционного налогового кредита.

В отдельных случаях инициатором возникновения налогового правоотношения может выступать как налоговый орган, так и налогоплательщик. Например, совместная сверка уплаченных налогоплательщиком налогов может быть проведена как по предложению налогового органа, так и налогоплательщика (абз. 3 п. 7 ст. 45 НК РФ).

О властности налогового органа (подчинении воли налогоплательщика) можно говорить, но не в рамках общего правила, а, скоpeе, как об исключительном случае, когда мы имеем дело с отклонением от правомерной модели поведения налогоплательщика, когда необходимо применять меры принуждения или когда налоговый орган своими действиями может внести изменения в ход событий, повлиять на налогоплательщика.

В.Г. Ледяев считает, что власть - это способность субъекта обеспечить подчинение объектов в соответствии со своими намерениями, и в связи с этим выделяет шесть форм властного подчинения: сила, принуждение, побуждение, убеждение, манипуляция, авторитет [3, с. 352].

\section{Налогоплательщик - кредитор}

Налоговые правоотношения являются сложносоставными и не сводятся исключительно к уплате налога. Налогоплательщик не всегда выступает в роли обязанного лица. Есть достаточно много примеров ситуаций, когда налогоплательщик, говоря языком цивилистов, выступает «кредитором», то есть обладает правом требования к налоговому органу.

Право требовать от должностных лиц налоговых и иных уполномоченных органов соблюдения законодательства о налогах и сборах при совершении ими действий в отношении налогоплательщиков прямозакреплено в пп. 10 п. 1 ст. 21 НК РФ. Трудно найти какой-либо другой отраслевой закон, где так же, как это установлено в данном подпункте, прямо было указано право «подчиняющейся» стороны требовать от должностных лиц государственных органов соблюдения законодательства.

Налогоплательщик может обращаться к налоговому органу с различными требованиями: требовать своевременного возврата сумм излишне уплаченных либо излишне взысканных налогов, пени, штрафов (пп. 5 п. 1 ст. 21, ст. 78 и 79 НК РФ), требовать от налоговых органов предоставления бесплатной информации (в том числе в письменной форме) о действующих налогах и сборах, формы налоговых деклараций (расчетов) и разъяснения о порядке их заполнения (пп. 1 п. 1 ст. 21 НК РФ) и т. д. И в этом отношении обязанной стороной выступает не налогоплательщик, а налоговый орган.

Можно выделить целый ряд компенсационно-восстановительных налоговых правоотношений, в которых государство выступа- 


\section{ТЕОРИЯ И ПРАКТИКА ГОСУДАРСТВЕННО-ПРАВОВОГО РАЗВИТИЯ}

ет в качестве обязанной стороны, а налогоплательщик - правомочной (п. 10 ст. 78, п. 9.2 ст. 76 , п. 5 ст. 79 , п. 10 ст. 176 , п. 10 ст. 176.1 , п. 3 ст. 203 НК РФ) [5]. Эти отношения складываются по поводу возмещения имущественных потерь налогоплательщика, в которых налоговый орган обязан начислять в его пользу проценты на неправомерно взысканные или несвоевременно возвращенные излишне уплаченные налоги, пени и штрафы.

«Как это ни кощунственно звучит, - отмечает М.Ю. Орлов, - но государство и его органы в рамках налоговых отношений имеют не только права, но и множество обязанностей, неисполнение которых является столь же незаконным, как и неисполнение налогоплательщиками своих обязанностей» [6].

Говоря о связанности свободы усмотрения в налоговых отношениях с наличием прямых нормативно-правовых предписаний налогового законодательства, Конституционный суд РФ в полной мере обратил свою позицию ко всем субъектам налогового права, а не только к налогоплательщику (абз. 5 п. 2 Определения КС РФ от 07 ноября 2008 г. № 1049O-O) [4]. Кроме того, существует ряд актов, в которых Конституционный суд РФ прямо и неоднократно указывал на связанность налогового органа законом в своей деятельности (Постановление КС РФ от 14 июля 2003 г. № 12-П [10], Постановление КС РФ от 16 июля 2004 г. № 14-П [11], Постановление КС РФ от 03 июня 2014 г. № 17-П [9] и др.).

\section{Налогоплательщик - партнер}

Признак властности, который безусловно присутствует в налоговых отношениях, не хотелось бы ставить на первое место и по другой причине. На протяжении всей истории налогообложения России укоренился стереотип, вполне возможно и не без оснований, согласно которому налогоплательщик представляется «каким-то “жуликоватым” субъектом, вечно стремящимся к уклонению, которого наше государство вечно ловит, пресекает и уличает, перекрывая законодательные лазейки», а само государство - «хозяином с палкой» $[2$, с. 24]. В данной парадигме налогоплательщик воспринимается не как партнер, кормилец государства, а как дойная корова.
Однако такое понимание является плодом фискально-репрессивного мышления, которое должно уходить в прошлое. Взамен предлагается модель партнерских отношений, основанная на взаимовыгодном сотрудничестве государства и хозяйствующих субъектов, что предполагает и соответствующее отношение к налогоплательщику. Абсолютно верно заметил С.Г. Пепеляев, что «лучший стимул - не угроза, а поощрение» [7, с. 4-5].

«Налогоплательщик должен стать достойной и уважаемой персоной, которая своими средствами обеспечивает деятельность государства $<\ldots>$, а государство - не диктатором, $<\ldots>$ a партнером, как это имеет место в гражданских правоотношениях» [2, с. 24]. Речь идет о такой ситуации, - указывает А.В. Брызгалин, - когда «"государство - для налогоплательщика", а не наоборот» [2, с. 24]. Тем более, что в России по заявлению А.П. Починка признаков откровенного уклонения от уплаты налогов нет, а процент собираемости налогов не уступает европейским странам [13].

\section{Выводы}

В такой ситуации признак властности должен уступить лидирующую позицию и принять вспомогательную роль. На смену принуждения в качестве основной идеи должно прийти поощрение и стимул.

\section{СПИСОК ЛИТЕРАТУРЫ}

1. Барышев, М. И. Финансовое право. Учебник / М. И. Барышев, Б. Н. Иванов, Е. А. Ровинский ; под ред. Е. А. Ровинского - М. : Юрид. лит., 1971. -392 c.

2. Брызгалин, А. В. Налоги и гражданское право: есть ли конфликт и что делать? / А. В. Брызгалин // Налоги и финансовое право. - 2009. № 4. - C. 17-24.

3. Ледяев, В. Г. Власть: концептуальный анализ / В. Г. Ледяев. - М. : «Российская политическая энциклопедия» (РОССПЭН), 2001. - 384 с.

4. Определение Конституционного суда РФ от 07 нояб. 2008 г. № 1049-О-О «Об отказе в принятии к рассмотрению жалобы общества с ограниченной ответственностью “Товарищ” на нарушение конституционных прав и свобод п. 5 ст. 168 и п. 5 ст. 173 Налогового кодекса Российской Федерации» // Beстник Конституционного суда РФ. - 2009. - № 2. 
5. Определение Конституционного суда РФ от 23 июня 2009 г. № 832-О-О «Об отказе в принятии к рассмотрению жалобы гражданина Дудкина Сергея Анатольевича на нарушение его конституционных прав положениями абзаца 1 п. 10 ст. 78 и абзаца 1 п. 5 ст. 79 Налогового кодекса Российской Федерации» (официально не опубликован). - Доступ из справ.-правовой системы «КонсультантПлюс» (дата обращения: 01.05.2018).

6. Орлов, М. Ю. Налог как форма разумного ограничения фискального суверенитета государства / М. Ю. Орлов // Финансовое право. - 2006. - № 2. С. 18-23. - Доступ из справ.-правовой системы «КонсультантПлюс» (дата обращения: 01.05.2018).

7. Пепеляев, С. Г. Платить с выгодой / С. Г. Пепеляев // Налоговед. - 2016. - № 3. - С. 4-5.

8. Петрова, Г. В. Налоговые отношения: теория и практика правового регулирования : автореф. дис. ... д-ра юрид. наук / Петрова Галина Владиславовна. - М., 2003. - 57 с.

9. Постановление Конституционного Суда РФ от 03 июня 2014 г. № 17-П «По делу о проверке конституционности положений п. 6 и 7 ст. 168 и п. 5 ст. 173 Налогового кодекса Российской Федерации в связи с жалобой ООО “Торговый дом “Камснаб”» // Вестник Конституционного суда РФ. - 2014. - № 5.

10. Постановление Конституционного суда РФ от 14 июля 2003 г. № 12-П «По делу о проверке конституционности положений ст. 4, п. 1 ст. 164, п. 1 и 4 ст. 165 Налогового кодекса Российской Федерации, ст. 11 Таможенного кодекса Российской Федерации и ст. 10 Закона Российской Федерации “О налоге на добавленную стоимость” в связи с запросами Арбитражного суда Липецкой области, жалобами ООО “Папирус”, ОАО “Дальневосточное морское пароходство” и ООО "Коммерческая компания "Балис"» // Вестник Конституционного суда РФ. - 2003. - № 5.

11. Постановление Конституционного суда РФ от 16 июля 2004 г. № 14-П «По делу о проверке конституционности отдельных положений части второй ст. 89 Налогового кодекса Российской Федерации в связи с жалобами граждан А.Д. Егорова и Н.В. Чуева» // Вестник Конституционного суда РФ. - 2004. - № 6.

12. Постановление Конституционного суда РФ от 17 дек. 1996 г. № 20-П «По делу о проверке конституционности п. 2 и 3 части первой ст. 11 Закона Российской Федерации от 24 июня 1993 г. “О федеральных органах налоговой полиции”» // Вестник Конституционного суда РФ. - 1996. - № 5.

13. Починок, А. П. Налогообложение нуждается в высокотехнологичных процессах / А. П. Починок. - Электрон. текстовые дан. - Режим доступа: http://nalogoved.ru/art/134.html. - Загл. с экрана.

14. Правовые акты в сфере налогообложения. Общие положения и специфика / Э. М. Цыганков, Б. Е. Тохтамуратов, А. В. Силкина, Т. А. Ашомко. -
М. : НПО «Вычислительная математика и информатика», 1999. - 64 с.

15. Ровинский, Е. А. Социалистические финансы и финансовое право / Е. А. Ровинский // Советское государство и право. - 1980. - № 8. - С. 40-48.

16. Советское финансовое право : учебник для вузов / отв. ред. Е. А. Ровинский. - М. : Госюриздат, 1961. $-350 \mathrm{c}$.

17. Финансовое право : учебник / под ред. И. И. Кучерова. - М. : Эксмо, 2011. - 590 с.

18. Цыганаш, В. Н. Судебная власть: понятие, технология, институт (концептуальный теоретикоправовой анализ) : монография / В. Н. Цыганаш. Ростов н/Д. : Изд-во ЮФУ, 2009. - 307 с.

19. Цыпкин, С. Д. Правовое регулирование налоговых отношений в СССР / С. Д. Цыпкин. - М. : Госюриздат, 1955. - $76 \mathrm{c.}$

20. Яговкина, В. А. Налоговое правоотношение (теоретико-правовой аспект) : автореф. дис. ... канд. юрид. наук / Яговкина Вита Александровна. М., 2003. - 24 c.

\section{REFERENCES}

1. Baryshev M.I., Ivanov B.N., Rovinskiy E.A. Finansovoe pravo. Uchebnik [Financial Law. Textbook]. Moscow, Yurid. lit. Publ., 1971. 392 p.

2. Bryzgalin A.V. Nalogi i grazhdanskoe pravo: est li konflikt i chto delat? [Taxes and Civil Law: Is There a Conflict and What to Do?]. Nalogi $i$ finansovoe pravo, 2009, no. 4, pp. 17-24.

3. Ledyaev V.G. Vlast: kontseptualnyy analiz [Power: a Conceptual Analysis]. Moscow, ROSSPEN Publ., 2001. 384 p.

4. Opredelenie Konstitutsionnogo suda RF ot 07 noyab. 2008 g. № 1049-O-O «Ob otkaze v prinyatii k rassmotreniyu zhaloby obshchestva s ogranichennoy otvetstvennostyu "Tovarishch" na narushenie konstitutsionnykh prav i svobod p. 5 st. 168 i p. 5 st. 173 Nalogovogo kodeksa Rossiyskoy Federatsii» [Decision of the Constitutional Court of the Russian Federation of 7 November 2008 No. 1049-O-O 'About Refusal to Consider of the Complaint of Tovarishch Ltd. about Violation of Constitutional Rights and Freedoms Item 5 of Article 168 and Item 5 of Article 173 of the Tax Code of the Russian Federation']. Vestnik Konstitutsionnogo suda RF, 2009, no. 2.

5. Opredelenie Konstitutsionnogo suda RF ot 23 iyunya 2009 g. № 832-O-O «Ob otkaze v prinyatii $k$ rassmotreniyu zhaloby grazhdanina Dudkina Sergeya Anatolyevicha na narushenie ego konstitutsionnykh prav polozheniyami abzatsa 1 p. 10 st. 78 i abzatsa 1 p. 5 st. 79 Nalogovogo kodeksa Rossiyskoy Federatsii» (ofitsialno ne opublikovan) [Decision of the Constitutional Court of the Russian Federation of 23 June 
2009 no. 832-O-O 'About Refusal to Consider of the Complaint of Sergey Anatolyevich Dudkin about Violation of His Constitutional Rights by Provisions of Paragraph 1 of Item 10 of Article 78 and Paragraph 1 Item 5 Article 79 of the Tax Code of the Russian Federation' (Upublished Version)]. Access from Reference Legal System 'KonsultantPlyus' (accessed 1 May 2018).

6. Orlov M.Yu. Nalog kak forma razumnogo ogranicheniya fiskalnogo suvereniteta gosudarstva [Tax as a Form of Reasonable Limitation of Fiscal Sovereignty of the State]. Finansovoe pravo, 2006, no. 2, pp. 18-23. Access from Reference Legal System 'KonsultantPlyus' (accessed 1 May 2018).

7. Pepelyaev S.G. Platit s vygodoy [Pay with Benefit]. Nalogoved, 2016, no. 3, pp. 4-5.

8. Petrova G.V. Nalogovye otnosheniya: teoriya $i$ praktika pravovogo regulirovaniya: avtoref. dis. ... d-ra yurid. nauk [Tax Relations: Theory and Practice of Legal Regulation. Dr. jurid. sci. abs. diss.] Moscow, 2003. 57 p.

9. Postanovlenie Konstitutsionnogo Suda RF ot 03 iyunya 2014 g. № 17-P «Po delu o proverke konstitutsionnosti polozheniy p. 6 i 7 st. 168 i p. 5 st. 173 Nalogovogo kodeksa Rossiyskoy Federatsii v svyazi s zhaloboy OOO "Torgovyy dom "Kamsnab") [Decision of the Constitutional Court of the Russian Federation of 3 June 2014 no. 17-P 'On the Case of Investigating the Constitutionality of Provisions of Items 6 and 7 of Article 168 and Item 5 of Article 173 of the Tax Code of the Russian Federation due to the Complaint of Kamsnab Trading House Ltd.]. Vestnik Konstitutsionnogo suda RF, 2014, no. 5.

10. Postanovlenie Konstitutsionnogo suda RF ot 14 iyulya 2003 g. № $12-\mathrm{P}$ «Po delu o proverke konstitutsionnosti polozheniy st. 4, p. 1 st. 164, p. 1 i 4 st. 165 Nalogovogo kodeksa Rossiyskoy Federatsii, st. 11 Tamozhennogo kodeksa Rossiyskoy Federatsii i st. 10 Zakona Rossiyskoy Federatsii "O naloge na dobavlennuyu stoimost"” v svyazi s zaprosami Arbitrazhnogo suda Lipetskoy oblasti, zhalobami OOO "Papirus", OAO "Dalnevostochnoe morskoe parokhodstvo" i OOO "Kommercheskaya kompaniya "Balis") [Decision of the Constitutional Court of the Russian Federation of 14 July 2003 no. 12-P 'On the Case of Investigating the Constitutionality of Provisions of Article 4, Item 1 of Article 164, Items 1 and 4 of Article 165 of the Tax Code of the Russian Federation, Article 11 of the Customs Code of the Russian Federation and Article 10 of the Law of the Russian Federation 'On Value Added Tax») due to Inquiries of Arbitration Court of the Lipetsk Region, Complaints of Papirus LLC, Dalnevostochnoe morskoe parokhodstvo JSC and Balis LLC]. Vestnik Konstitutsionnogo suda RF, 2003, no. 5.

11. Postanovlenie Konstitutsionnogo suda RF ot 16 iyulya 2004 g. № 14-P «Po delu o proverke konstitutsionnosti otdelnykh polozheniy chasti vtoroy st. 89 Nalogovogo kodeksa Rossiyskoy Federatsii v svyazi s zhalobami grazhdan A.D. Egorova i N.V. Chueva» [Decision of the Constitutional Court of the Russian Federation of 16 July 2004 no. 14-P 'On the Case of Investigating the Constitutionality of Separate Provisions of Part Two of Article 89 of the Tax Code of the Russian Federation due to Complaints of Citizens A. D. Egorov and N. V. Chuev']. Vestnik Konstitutsionnogo suda RF, 2004, no. 6 .

12. Postanovlenie Konstitutsionnogo suda RF ot 17 dek. 1996 g. № 20-P «Po delu o proverke konstitutsionnosti p. 2 i 3 chasti pervoy st. 11 Zakona Rossiyskoy Federatsii ot 24 iyunya $1993 \mathrm{~g}$. "O federalnykh organakh nalogovoy politsii"»" [Decision of the Constitutional Court of the Russian Federation ' $O n$ the Case of Investigating the Constitutionality of Items 2 and 3 of Part One of Article 11 of the Law of the Russian Federation of 24 June 1993 "About Federal Bodies of Tax Police"']. Vestnik Konstitutsionnogo suda RF, 1996, no. 5.

13. Pochinok A.P. Nalogooblozhenie nuzhdaetsya $v$ vysokotekhnologichnykh protsessakh [Taxation Requires High-Tech Processes]. URL: http:// nalogoved.ru/art/134.html. (accessed 1 May 2018).

14. Tsygankov E.M., Tokhtamuratov B.E., eds. Pravovye akty $v$ sfere nalogooblozheniya. Obshchie polozheniya i spetsifika [Legal Acts in the Field of Taxation. General Provisions and Specificity]. Moscow, Vychislitelnaya matematika i informatika Publ., 1999. $64 \mathrm{p}$.

15. Rovinskiy E.A. Sotsialisticheskie finansy i finansovoe pravo [Socialist Finance and Financial Law]. Sovetskoe gosudarstvo i pravo, 1980, no. 8, pp. 40-48.

16. Rovinskiy E.A., ed. Sovetskoe finansovoe pravo [Soviet Financial Law]. Moscow, Gosyurizdat Publ., 1961.350 p.

17. Kucherov I.I., ed. Finansovoe pravo [Financial Law]. Moscow, Eksmo Publ., 2011. 590 p.

18. Tsyganash V.N. Sudebnaya vlast: ponyatie, tekhnologiya, institut (kontseptualnyy teoretikopravovoy analiz): monografiya [Judicial Power: Concept, Technology, Institute (Conceptual Theoretical and Legal Analysis)]. Rostov-on-Don, YuFU Publ., 2009. 307 p.

19. Tsypkin S.D. Pravovoe regulirovanie nalogovykh otnosheniy $v$ SSSR [Legal Regulation of Tax Relations in the USSR]. Moscow, Gosyurizdat Publ., 1955. 76 p.

20. Yagovkina V.A. Nalogovoe pravootnoshenie (teoretiko-pravovoy aspekt): avtoref. dis. ... kand. yurid. nauk [Tax Legal Relationship (Theoretical and Legal Aspect). Cand. jurid. sci. abs. diss.] Moscow, 2003. 24 p. 


\section{Information about the Author}

Sergey A. Yadrikhinskiy, Candidate of Sciences (Jurisprudence), Associate Professor, Department of Administrative and Financial Law, North-Western Institute (Branch) of Kutafin Moscow State Law University, Mira St., 32, 160001 Vologda, Russian Federation, syadr@yandex.ru.

\section{Информация об авторе}

Сергей Александрович Ядрихинский, кандидат юридических наук, доцент кафедры административного и финансового права, Северо-Западный институт (филиал) Университета им. О. Е. Кутафина (МГЮА), ул. Мира, 32, 160001 г. Вологда, Российская Федерация, syadr@yandex.ru. 